\title{
The roles of past behavior and health beliefs in predicting medication adherence to a statin regimen
}

This article was published in the following Dove Press journal:

Patient Preference and Adherence

5 September 2012

Number of times this article has been viewed

\author{
Todd D Molfenter' \\ Abhik Bhattacharya ${ }^{2}$ \\ David H Gustafson' \\ 'Center for Health Enhancement \\ Systems Studies (CHESS), Madison, \\ WI, USA; ${ }^{2}$ Blue Health Intelligence, \\ Chicago, IL, USA
}

Correspondence: Todd Molfenter

Center for Health Enhancement Systems Studies (CHESS), 4I03 Mechanical Engineering Building, I513 University Avenue, Madison, WI 53706, USA

Tel +l 6082621685

$\mathrm{Fax}+$ I 608890 |438

Email todd.molfenter@chess.wisc.edu
Purpose: Current medication-adherence predictive tools are based on patient medication-taking beliefs, but studying past behavior may now be a more explanatory and accessible method. This study will evaluate if past medication-refill behavior for a statin regimen is more predictive of medication adherence than patient medication-taking health beliefs.

Patients and methods: This prospective longitudinal study was implemented in a national managed care plan in the United States. A group of 1433 statin patients were identified and followed for 6 months. Medication-taking health beliefs, collected from self-reported mail questionnaires, and past medication-refill behavior, using proportion of days covered (PDC), were collected prior to 6-month follow-up. Outcomes were measured using categorical PDC variable (of adherence, $\mathrm{PDC} \geq 85 \%$, versus nonadherence, $\mathrm{PDC}<85 \%$ ), with model fit estimated using receiver operator characteristic analysis.

Results: The area under the receiver operator characteristic curve for past behavior $\left(A_{z}=0.78\right)$ was significantly greater $(P<0.05)$ than for patient health beliefs $\left(\mathrm{A}_{\mathrm{z}}=0.69\right)$, indicating that past prescription-refill behavior is a better predictor of medication adherence than prospective health beliefs. Among health beliefs, the factor most related to medication adherence was behavioral intent (odds ratio, 5.12; 95\% confidence interval, 1.84 to 15.06). The factor most strongly related to behavioral intent was impact of regimen on daily routine (odds ratio, 3.3; $95 \%$ confidence interval, 1.41 to 7.74 ).

Conclusion: Electronic medical records and community health-information networks may make past prescription-refill rates more accessible and assist physicians with managing medicationregimen adherence. Health beliefs, however, may still play an important role in influencing medication-taking behaviors.

Keywords: medication adherence, habit, health beliefs

\section{Introduction}

Heart disease remains the top cause of global mortality. ${ }^{1}$ High cholesterol levels are one of the major controllable risk factors for heart disease, ${ }^{2,3}$ with statin-medication therapy considered a primary treatment for hypercholesterolemia. ${ }^{4}$ Using statin medications reduces major vascular events (defined by coronary death, nonfatal myocardial infarction, coronary revascularization, or stroke) by $20 \%{ }^{5}$ Yet just $40 \%-60 \%$ of those on a statin regimen adhere to it sufficiently to experience the benefits of the treatment. 6,7 Despite the potential benefits of medication adherence, tools to predict or influence medication adherence to a statin regimen are not part of standard physician practice in outpatient settings. ${ }^{8-10}$

Medication-adherence assessment tools that can help physicians anticipate nonadherence behavior have existed for over a decade, ${ }^{11,12}$ with current models building 
on these frameworks. ${ }^{13,14}$ These tools are based on patient beliefs generated from various social-cognitive models such as the Health Belief Model, ${ }^{15}$ the Transtheoretical Model, ${ }^{16}$ and the Theory of Reasoned Action ${ }^{17}$ and its revision, the Theory of Planned Behavior. ${ }^{18}$

Several beliefs are commonly used to model medication adherence. A specific cognitive belief that supports adherence to a statin regimen is that the medication will improve health by reducing symptoms or clinical markers such as total, HDL, and LDL cholesterol readings. ${ }^{19}$ Cognitive beliefs related to statin nonadherence are beliefs about the perceived and actual regimen side effects, ${ }^{20}$ complexity, ${ }^{21}$ effects on daily routine, ${ }^{22}$ and costs. ${ }^{23}$

Social beliefs related to medication adherence have focused on the support available from family and friends, as well as the support from clinical professionals. ${ }^{24,25}$ Individuals with social support from family and friends can be more likely to adhere to their medication regimens. ${ }^{26}$ Research on the communication patterns between patients and their clinical providers demonstrates the important role the provider plays in statin-adherence behaviors ${ }^{27}$ and medical outcomes. ${ }^{28}$ In medical care, the patient playing an active role in establishing the regimen, ${ }^{29-31}$ mutual agreement on the regimen choice, ${ }^{32,33}$ and follow-up plans that foster continuity and accountability ${ }^{34-36}$ all enhance the likelihood of regimen adherence.

Extensive research on the impact of social-cognitive health beliefs on medication adherence and their use in validated predictive tools exists. The patient completes these two- to four-item questionnaires in the physician's office. However, physicians have not integrated them into daily practice due to their perceived lack of usefulness and the time required to administer them. ${ }^{37,38}$

\section{Role of past behavior}

One of the prevailing arguments against the use of socialcognitive models to predict medication adherence is that they do not consider past behavior or habit, which has been raised as a more plausible approach to explaining medication nonadherence. ${ }^{39}$ Habit theory states that habits are not cognitive decision-making events, but "tendencies to repeat responses given a stable supporting context." ${ }^{39}$ This approach contends that a habit formed through repeated behaviors is more predictive of activity than the cognitive beliefs that influence decision making. ${ }^{40}$ Cognitive-behavioral theorists would counter that all behavior is based on reasoned action. A study by Bamberg et $\mathrm{l}^{41}$ tested the predictive validity of past behavior as compared to beliefs based on the Theory of Planned Behavior. In this study, students received free bus passes for a semester to see if they would break the environmentally unfriendly habit of driving a car to campus. The study discovered that behavior did change and concluded, "Only when circumstances remain relatively stable does past behavior make a significant contribution to the prediction to later action." ${ }^{41}$

Research on the role of past behaviors has focused primarily on consumer behavior and is becoming a subject of interest in understanding health behaviors such as medication adherence..$^{42}$ Trials have noted that past refill behavior can be an indicator of future medication-adherence behavior in patients with cardiovascular conditions. ${ }^{43-45}$ How past behaviors compare with cognitive beliefs in predicting statin-medication adherence is unknown, since no known research compares these two predictors. Research on past behavior could have implications for physicians managing patients engaged in long-term regimens for chronic disease conditions. We hypothesized that past behavior related to medication adherence as measured by past prescription-refill rates would be a better predictor of medication adherence than a set of patient health beliefs selected by a panel of medication-adherence experts.

\section{Methods}

The study team recruited 1433 United Healthcare Plan members from a national sample of 2789: Georgia $(n=75)$, Ohio $(n=592)$, North Carolina $(n=256)$, Arizona $(n=121)$, Rhode Island ( $n=146)$, and Missouri $(n=243)$. To be eligible for the study, participants had to be aged 21 years or older; have submitted a claim for HMG-CoA reductase inhibitors (statins) between August 1, 2002 and January 31, 2003; had United Healthcare as their primary insurer; and have been enrolled continuously in the health plan for 6 months extending through the last month used for sample selection. United Healthcare Plan ran a query of their database to identify enrollees that met these characteristics. Once the eligible participants were identified, demographic data were collected, as well as days of statin medication supplied for the baseline period. For the medication-adherence outcome period, days of medication supply and follow-up duration was supplied for each participant. Procedures were in place to detect if the enrollee had switched statin medications; the calculated proportion of days covered (PDC) incorporated both statin medications. If a participant left the plan, the PDC was calculated on the truncated data. The pharmacy-claims database used to identify eligible participants contained all medications paid for by the health plan for an enrolled member. This database is thought to be nearly complete, since it includes 
all medication transactions for an individual except for medications received through free samples or friends, which are projected to be minimal. ${ }^{46}$ The individuals identified in the sample selection process were contacted by mail and asked to complete the University of Wisconsin Institutional Review Board-approved self-report survey instrument, which collected information regarding their beliefs and intentions toward adherence to the targeted medication.

\section{Measures}

The United Healthcare Plan patient-administration database supplied the sociodemographic factors of age, sex, race, and education. Past behavior was measured using the 6-month baseline prescription-refill PDC for the time period of August 1, 2002 to January 31, 2003. The United Healthcare Plan pharmacy-claims database provided a listing of each statin medication-refill date, the days of medication supplied, and type of statin for each study participant. The PDC measure divides days supplied by total days for a given evaluation period and indicates the maximum amount of medication a patient could have taken in a given time period. ${ }^{47}$ The underlying assumption is that a patient is either underusing or has stopped using the medication when his or her medication is not refilled as expected. Oversupply is truncated at 100\%, since this measure does not address overuse of medication.

Because set dates were used to begin and end the mean medication-possession ratio period, the database was queried 90 days before August 1, 2002 so that any 30 or 90 refills dispensed prior to the baseline that carried over into the PDC period could be included in the PDC calculation. For instance, a patient who received 30-day supply on July 31 would be credited for 29 days of medication availability for the PDC calculation. Similarly, for the PDC calculation, a patient who received a 30-day supply on the last day of the PDC calculation period would only be credited for one day of medication availability.

The health beliefs were measured by a survey mailed during the 2 months following the collection of the baseline data and before the collection of the medication-adherence data. The health beliefs included in the survey were based on the Health Beliefs Matrix (Table 1) constructed by an expert panel using an evidence-based process from the decision science literature to identify the factors most related to medication adherence. ${ }^{48}$ The 15 -member panel included experts from medicine, nursing, psychiatry, pharmacy, and public health, who each had multiple peer-reviewed publications on medication regimens. The expert panel yielded a set of cognitive beliefs that assessed perceived risk of poor health without medication, medication benefits, side effects, patient understanding of regimen, impact of regimen on daily routine, and having sufficient money to afford medications. The social beliefs selected were social support from friends and family and patient-doctor dialogue. Patient-doctor dialogue was assessed using a three-item scale. All other social and cognitive beliefs were measured using single-item scales. A factor analysis of the study's health beliefs found three single-item variables related to patient-physician communication had similar loadings on medication adherence. All variables were assessed using a four-point scale ranging from 1 (strongly disagree) to 4 (strongly agree). The variables assessing patient-physician regimen decision making, discussion of side effects, and development of a medication follow-up plan were structured to create the patient-doctor dialogue scale (alpha $=0.71)$. The construct of behavioral intent was also included in the study because it is an indication of an individual's readiness to perform a given behavior and is assumed to be an immediate antecedent of behavior. ${ }^{49}$

Table I Health belief matrix

\begin{tabular}{ll}
\hline Cognitive beliefs & Belief statements \\
\hline $\begin{array}{l}\text { Perceived risk of poor health } \\
\text { Perceived benefit }\end{array}$ & I believe there is a chance of poor health if I fail to take the medication as prescribed. \\
I believe the regimen has worked and met its goal. \\
Side effects & Side effects were present and prevented a valued activity. \\
Understanding of regimen & I completely understand my regimen. \\
Impact on daily routine & Taking my medication interrupts my daily routine. \\
Financial resources & I do not have adequate money to pay for my medications. \\
Behavioral intent & I intend to take the medication exactly as prescribed. \\
Social beliefs & \\
Patient/clinician regimen dialogue & The clinician and I have mutually agreed upon the goals and the regimen for the medication. \\
& The clinician and I have discussed the potential side effects of the medication and how to deal with them. \\
Social support (from family/friends) & The clinician established a follow-up plan for medication regimen.
\end{tabular}

Note: a Four-point scale ranging from I (strongly disagree) to 4 (strongly agree). 
Refill information from United Healthcare claims database was used to calculate the medication adherence outcome variable for the 6-month fixed period from April 1 to September 30, 2003. A 6-month follow-up period has been used to assess the impact of health beliefs on adherence behavior. ${ }^{20}$ In addition, within 6 months of initiation of a statin regimen, mean PDC can already be as low as $56 \%{ }^{43}$ The procedures described to calculate the baseline PDC were also applied to calculate the medication-adherence outcome variable. The categorical PDC in the outcome variable used the cut-point of $<0.85$ for nonadherence and $\geq 0.85$ for adherence, to create a dichotomous variable using criteria set by Wetzels et al. ${ }^{50}$ Medication-adherence measures generated from pharmacy-claims data have been correlated with clinical outcomes across several studies. ${ }^{46,51-56}$

\section{Data analysis}

Categorical sociodemographic data are reported as percentages and continuous variables as means. The study team used a receiver operator characteristic (ROC) analysis to determine model fit between health beliefs (Table 1) and past adherence behavior (using baseline PDCs derived from prescriptionrefill records) with actual medication use. ROC analysis is a method to measure predictive accuracy ${ }^{57}$ and is used to assess the accuracy of medication-adherence measures. ${ }^{58}$ With the ROC area under the curve, a score of 1.0 means perfect prediction and a 0.5 gives the same result as random guessing. A score of 0.70 or greater is considered to be an indication that the model in question has significant predictive power. ${ }^{59}$ The ROC was calculated using logistic regression models.

Last, the study team conducted two additional multivariate logistic regression analyses. The first compared the study's health beliefs with medication use, and the second compared the study's health beliefs with behavioral intent. The health-belief predictors were made dichotomous for the odds ratio analysis by developing disagree (responses 1 and 2) and agree (responses 3 and 4) survey responses for each factor. These analyses tested each of the health-belief predictors' independent effects on behavioral intent to take the medication and practice medication adherence. SPSS 19.0 (IBM Corporation, Armonk, NY) was used to examine all statistical analyses.

\section{Results}

The return rate for the health-beliefs survey was $51.3 \%$, with 1433 eligible participants and 1356 ineligible participants from a sample of 2789. Patients became ineligible when they failed to return the study's health-medication beliefs survey, a physician discontinued their statin prescription, they discontinued participation in the United Healthcare health plan, or someone other than the patient completed the survey instrument. Of the eligible participants, 52.4\% were older than 55 years, $57.5 \%$ were male, $90.8 \%$ had graduated from high school, and 26\% were married. There were statistical differences between the eligible and ineligible samples. The eligible sample was 2 years older and had 3.2\% more females (Table 2) than the ineligible sample. In addition, the eligible sample had a median medication adherence of $82.7 \%$ at baseline, while the ineligible sample had a mean medication adherence of $78.3 \%$.

The mean medication adherence for the outcome variable was $78.8 \%$, with a median of $88.0 \%$. The categorical PDC used the cut-point of $<0.85$ for nonadherence and $\geq 85$ for adherence. The proportion of the participants with medication adherence ( $<85 \%$ in the outcome variable) was $43.8 \%$, and was $45.9 \%$ in the baseline measurement.

\section{Comparison of past behavior to health beliefs}

The area under the ROC curve (or c-statistics) for past behavior $\left(\mathrm{A}_{\mathrm{z}}=0.78\right)$ was significantly greater $(P=<0.05)$ than for patient health beliefs $\left(A_{z}=0.69\right)$ (Figure 1). A model that included both health beliefs and past behavior had an ROC area under the curve result that was only slightly better than past behavior alone $\left(A_{z}=0.79\right)$.

\section{Health-belief analysis}

Even though the combination of health beliefs was not more predictive of medication adherence than past behavior, three of the nine beliefs were associated with poor adherence, at $P=<0.05$ in the multivariable analysis (Table 3 ).

Table 2 Sociodemographic characteristics of the participants at baseline $(n=2789)$

\begin{tabular}{lll}
\hline Subject characteristics & Eligible sample & Ineligible sample \\
\hline $\begin{array}{l}\text { Sample size } \\
\text { Sociodemographics }\end{array}$ & 1433 & 1356 \\
Age (years) & 54.2 & \\
(standard deviation) & $(9.79)$ & $52.2^{\mathrm{a}}$ \\
(median) & $(54.9)$ & $(9.97)$ \\
Sex (\% females) & 43.7 & $(53.0)$ \\
Race (\% nonwhite) & 8.7 & $40.5^{\mathrm{a}}$ \\
Education (years) & 13.6 & $\mathrm{NA}$ \\
(standard deviation) & $(1.9)$ & $\mathrm{NA}$ \\
(median) & $(13.5)$ & $\mathrm{NA}$ \\
Medication adherence & $82.7 \%$ & $\mathrm{NA}$ \\
(standard deviation) & $(18.5 \mathrm{I})$ & $78.26 \%{ }^{\mathrm{b}}$ \\
(median) & $(88.0)$ & $(31.75)$ \\
\hline
\end{tabular}

Notes: ${ }^{\mathrm{P}} \mathrm{P}<0.05$; ${ }^{\mathrm{b} P}<0.001$. 


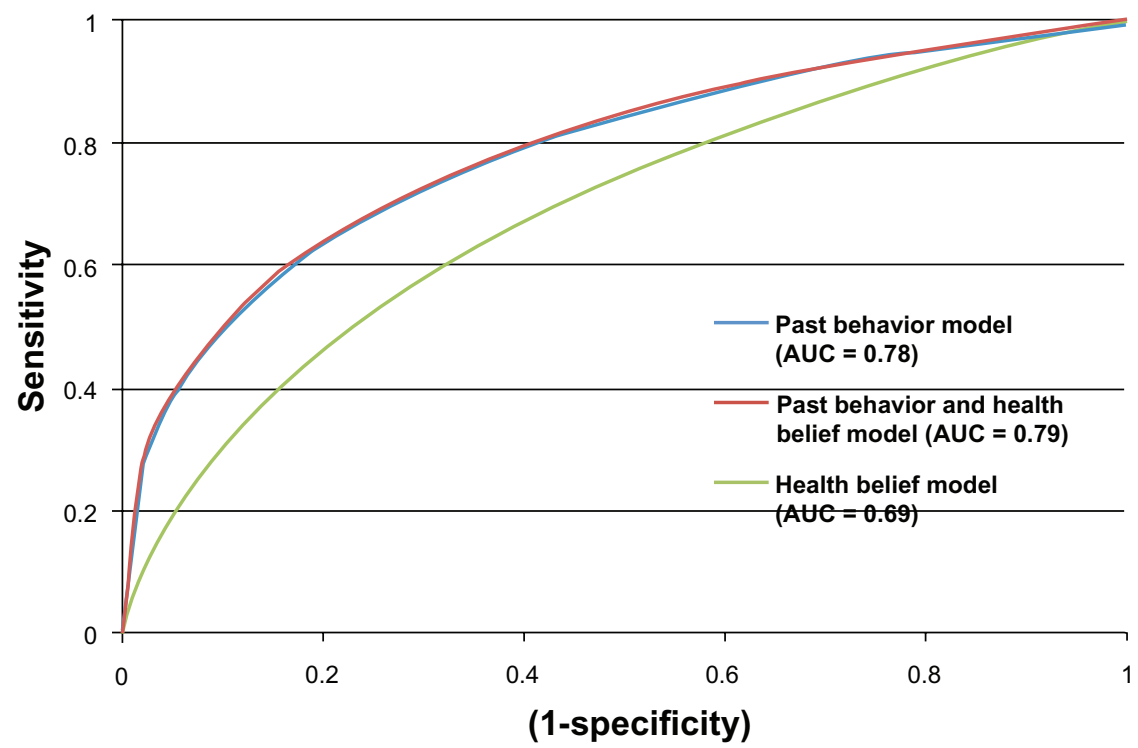

Figure I Receiver operator characteristic (ROC) curves illustrating the predictive accuracy of beliefs and past behavior for medication adherence.

These included the beliefs of perceived risk of poor health without regimen, not enough financial resources, and behavioral intent. The single health-belief factor that most strongly predicted medication adherence was behavioral intent (odds ratio, 5.12; 95\% confidence interval [CI], 1.84 to 15.06). This result is consistent with the Theory of Planned Behavior hypothesis that all beliefs combine to create behavioral intent to conduct the targeted behavior. ${ }^{49}$ In the multivariate analysis, the belief most strongly associated with behavioral intent was whether the new regimen aligned with or upset a patient's daily routine (odds ratio, 3.3; 95\% CI, 1.41 to 7.74 ).

\section{Discussion}

For clinicians, the findings presented in this research suggest that a patient's prescription-refill information (past behavior) predicts the likelihood of future adherence to a statin regimen. To health interventionists, studying past behavior is not a novel approach. Pharmacists have used past prescription-refill behavior to identify patients in need of additional counseling and education.$^{60}$ Health insurance companies have attempted to use past acute clinical events to anticipate future health care episodes so they can provide additional counseling on preventive care.$^{61}$ Thus far, however, this approach has only been demonstrated to improve adherence rates with patients experiencing depression. ${ }^{62}$ Within physician office settings, perhaps because access to meaningful past medication history has not been available to physicians and nurses, the use of brief questionnaires based on health beliefs continues to be advanced as the most reasonable approach for predicting medication adherence to existing regimens in a clinical setting. ${ }^{13}$

The role of past behavior and habit as compared to health beliefs has been an issue of inquiry for theorists trying to understand and predict individual behavior. ${ }^{49,63}$ Bamberg et $\mathrm{al}^{41}$ described habit theory as being most applicable to repetitive behaviors in stable environments and past behavior as less of a predictor of future behavior than beliefs and reasoning only when there was a significant change in the environment. These findings suggest that patients on

Table 3 Multivariate predictors of medication adherence $(P<0.05)$

\begin{tabular}{|c|c|c|c|c|c|}
\hline \multirow[t]{2}{*}{ Belief category } & \multirow[t]{2}{*}{ Belief } & \multicolumn{2}{|c|}{ Behavioral intent } & \multicolumn{2}{|c|}{ Medication adherence } \\
\hline & & OR & $95 \% \mathrm{Cl}$ & OR & $95 \% \mathrm{Cl}$ \\
\hline \multirow[t]{5}{*}{ Cognitive belief } & Perceived risk of poor health & 1.91 & $1.13-3.21$ & 1.82 & $1.26-2.63$ \\
\hline & Perceived benefit & $\mathrm{I} .77$ & $1.13-2.74$ & NS & NS \\
\hline & Side effects & 1.68 & $1.19-5.59$ & NS & NS \\
\hline & Impact on daily routine & 3.30 & $1.4 \mid-7.74$ & NS & NS \\
\hline & Not enough financial resources & 1.93 & $1.23-3.03$ & $1.5 \mathrm{l}$ & $1.02-2.40$ \\
\hline Social belief & Quality of patient/doctor regimen dialogue & 1.98 & $1.17-3.36$ & NS & NS \\
\hline Behavioral intent & Intent to take medication & NA & NA & 5.12 & $1.84-11.06$ \\
\hline
\end{tabular}

Abbreviations: $\mathrm{OR}$, odds ratio; $\mathrm{Cl}$, confidence interval. 
a long-term medication regimen demonstrate long-term, stable behavior, with past behavior being a strong predictor of future behavior.

The question these findings raise, however, is what the clinician should do to assist a patient if past prescriptionrefill rates indicate that the patient is nonadherent. Examining the patient's health beliefs may offer a solution. Behavioral intent was the strongest predictor of medication-adherence behavior (odds ratio, 5.12; 95\% CI, 1.84 to 15.06). For clinicians doubting whether or not patients plan to take their medications, posing the question, "Do you intend to take your medications exactly as prescribed?" could provide insight. The question most predictive of behavioral intent was "Does taking this medication impact your daily routine?" (impact on daily routine: odds ratio, 3.3; 95\% CI, 1.41 to 7.74). Potential interventions for reducing this barrier are done to simplify regimen complexity whenever possible or to provide behavioral strategies that limit the impact of the medication regimen on daily routine. For example, pharmacists have found that using motivational interviewing to identify and overcome barriers to medication adherence can improve medication adherence among patients initiating statin therapy. ${ }^{64}$ For the insured population represented in this study, the one significant effect on medication-taking behaviors (odds ratio, 1.51; 95\% CI, 1.02 to 2.40) was caused by the patients' belief that they lacked the financial resources to pay for their medication. One finding from this study is that insurance coverage does not eliminate limited financial resources as a barrier to medication adherence.

Factors related to cognitive beliefs were significantly related to medication adherence, yet the social factors as constructed had limited influence on medication-taking behaviors. Social support had no significant impact on medication taking. Also, the quality of patient-doctor regimen dialogue had an effect only on behavioral intent, not on actual use. This research demonstrates that, in this population, social factors may have a limited role in medication-taking behavior and are less prevalent than factors such as impact on daily routine, perceived risk of poor health if the regimen is not followed, side effects, and the inability to afford medication for statin regimens.

\section{Study limitations}

The use of pharmacy prescription-refill records gives the maximum possible amount of medications a patient can take, but the purchase of medications does not guarantee consumption. However, the concerns about nonconsumption have become less of an issue with the increase in studies establishing the association between medication prescription refills and clinical outcomes. ${ }^{51,53,55}$ The use of a 6-month follow-up period is not ideal, since statin nonadherence rates are projected to increase until 5 years beyond the initiation of a statin regimen. ${ }^{43}$ At 6 months postinitiation, statin PDC is $56 \%$, as compared to $44 \%$ PDC at 5 years postinitiation. ${ }^{43}$ Based on these values, the authors believed a considerable amount of nonadherence behavior could be detected by 6 months. The use of pharmacy-claims data for the past behavior and medication-adherence behavior does introduce method variance, since both are measured by the same method. The use of pharmacy-refill records and brief health-beliefs questionnaires were selected as independent variables because these are two tools available to physicians and because the study's purpose was to test the ability of these available tools to predict medication adherence. Future research could limit this effect by using another valid measure of medication adherence, such as the Medication Events Monitoring System (MEMs). The dichotomous outcome variable used to measure medication adherence will not be as sensitive as a continuous variable. Most medicationadherence research, however, does declare whether the patient is adherent or nonadherent, based on a predefined measure. ${ }^{51}$ Also, all the health beliefs but those related to physician communication were assessed using a single-item variable. This study used single-item variable measures to replicate brief health-belief measures that can be administered in a busy physician practice where it would not be practical to apply scales. Although the health-belief measures represent common factors associated with medication adherence that were worded and scaled by medication-adherence experts, the specific metrics applied had not been previously validated. Future studies could consider the use of validated healthbelief scales. Another limitation is that the study does not focus on newly prescribed medications or issues specific to the underserved and uninsured. It is possible health beliefs may be more predictive of medication adherence under these conditions. However, the authors did project that past refill adherence may be less pronounced in patients new to a regimen, due to the decreases in adherence behavior that occur during the first 6 months of a statin regimen. This should be tested in future trials.

For those conducting research related to the Theory of Planned Behavior, this study replaced social norms with social supports from the physicians and from the patient's family. The impetus for altering this variable was that social norms have not been found to be related to medicationtaking behaviors, while physician and family supports have. ${ }^{65}$ 
Finally, the data were calculated using patients on statin regimens. Tests on other health conditions will assess the generalizability of the results to other disease states.

\section{Future implications}

This study demonstrated the significant role that past behavior, based on prescription-refill rates, can play in predicting medication-adherence behavior $(\mathrm{ROC}=0.78)$. These findings could change how clinicians manage medication-adherence behaviors. In the past, clinicians had limited access to medication prescription-refill information. At present, $35 \%$ of physician office practices possess a medical record that lists medications prescribed to a patient in the United States. ${ }^{66}$ This percentage is expected to rise to $79 \%$ due to the financial incentives Medicare and Medicaid are offering through their electronic health-record incentive programs. ${ }^{67}$ However, the presence of an electronic medical record will not always mean access to pharmacy prescription-refill records. Electronic medical records may not contain medication-refill data, because that information is not obtainable. Clinics with their own pharmacy-claims payment service will have access to medication-refill information, but other clinics will not have timely access to these data until a community health information network is established in their region. ${ }^{68}$ Once medicationrefill information is available in the electronic medical record, the information may still not be utilized as part of patient office visits, because the information is not integrated into the clinician's traditional workflow or is not in a format that aids clinical decision making. ${ }^{69}$ Accordingly, future health-information regulation and health-record designs should facilitate the use of these data in daily physician practice. Once widely available, past prescription-refill records could play a role in reducing the large gap between those who take their medications as prescribed and those who do not. Moreover, the role of past behavior should be tested for other health behaviors, such as increasing physical activity and changing diet to determine their role in identifying individuals that could benefit from interventions based on beliefs and validated methods.

\section{Acknowledgment/disclosure}

An unrestrictive grant was used so Merck and Co (Whitehouse Station, NJ) would have no direct influence over the scientific direction of the study or results reported. The authors report no other conflicts of interest in this work.

\section{References}

1. World Health Organization. The Global Burden of Disease: 2004 Update. Geneva, Switzerland: WHO Press; 2008.
2. Stampfer MJ, Krauss RM, Ma J, et al. A prospective study of triglyceride level, low-density lipoprotein particle diameter, and risk of myocardial infarction. JAMA. 1996;276(11):882-888.

3. Manninen V, Tenkanen L, Koskinen P, et al. Joint effects of serum triglyceride and LDL cholesterol and HDL cholesterol concentrations on coronary heart disease risk in the Helsinki Heart Study. Implications for treatment. Circulation. 1992;85(1):37-45.

4. heart.org [homepage on the Internet]. Drug therapy for cholesterol. Dallas, TX: American Heart Association, Inc; 2012 [updated June 14, 2012]. Available from: http://www.heart.org/HEARTORG/Conditions/ Cholesterol/PreventionTreatmentofHighCholesterol/Drug-Therapy-forCholesterol_UCM_305632_Article.jsp. Accessed July 25, 2011.

5. Cholesterol Treatment Trialists' Collaboration (CTT). Efficacy and safety of cholesterol-lowering treatment: prospective meta-analysis of data from 90,056 participants in 14 randomised trials of statins. Lancet. 2005;366(9493):1267-1278.

6. Huser MA, Evans TS, Berger V. Medication adherence trends with statins. Adv Ther. 2005;22(2):163-171.

7. Jackevicius CA, Mamdani M, Tu JV. Adherence with statin therapy in elderly patients with and without acute coronary syndromes. JAMA. 2002;288(4):462-467.

8. Ho PM, Bryson CL, Rumsfeld JS. Medication adherence: its importance in cardiovascular outcomes. Circulation. 2009;119(23):3028-3035.

9. LaRosa JH, LaRosa JC. Enhancing drug compliance in lipid-lowering treatment. Arch Fam Med. 2000;9(10):1169-1175.

10. Vermeire E, Hearnshaw H, Van Royen P, Denekens J. Patient adherence to treatment: three decades of research. A comprehensive review. J Clin Pharm Ther. 2001;26(5):331-342.

11. Morisky DE, Green LW, Levine DM. Concurrent and predictive validity of a self-reported measure of medication adherence. Med Care. 1986;24(1):67-74.

12. Svarstad BI, Chewning BA, Sleath BL, Claesson C. The brief medication questionnaire: a tool for screening patient adherence and barriers to adherence. Patient Educ Couns. 1999;37(2):113-124.

13. McHorney CA. The adherence estimator: a brief, proximal screener for patient propensity to adhere to prescription medications for chronic disease. Curr Med Res Opin. 2009;25(1):215-238.

14. Mahler C, Hermann K, Horne R, et al. Assessing reported adherence to pharmacological treatment recommendations. Translation and evaluation of the Medication Adherence Report Scale (MARS) in Germany. J Eval Clin Pract. 2010;16(3):574-579.

15. Rosenstock IM. The health belief model and preventive health behavior. Health Educ Monogr. 1974;2:354-386.

16. Prochaska JO, Velicer WF. The transtheoretical model of health behavior change. Am J Health Promot. 1997;12(1):33-48.

17. Ajzen I, Fishbein M. Understanding Attitudes and Predicting Social Behavior. Englewood Cliffs, NJ: Prentice-Hall; 1980.

18. Ajzen I. From intention to actions: a theory of planned behavior. In: Kuhl J, Beckmann J, editors. Action-control: From Cognition to Behaviour. Heidelberg: Springer; 1985:11-39.

19. O'Carroll R, Whittaker J, Hamilton B, Johnston M, Sudlow C, Dennis M. Predictors of adherence to secondary preventive medication in stroke patients. Ann Behav Med. 2010;41(3):383-390.

20. Mann DM, Allegrante JP, Natarajan S, Halm EA, Charlson M. Predictors of adherence to statins for primary prevention. Cardiovasc Drugs Ther. 2007;21(4):311-316.

21. Ellis JJ, Erickson SR, Stevenson JG, Bernstein SJ, Stiles RA, Fendrick AM. Suboptimal statin adherence and discontinuation in primary and secondary prevention populations. $J$ Gen Intern Med. 2004;19(6):638-645.

22. Bosworth HB. Improving Patient Treatment Adherence: A Clinician's Guide. New York: Springer; 2010.

23. Doshi JA, Zhu J, Lee BY, Kimmel SE, Volpp KG. Impact of a prescription copayment increase on lipid-lowering medication adherence in veterans. Circulation. 2009;119(3):390-397.

24. Zolnierek KBH, DiMatteo MR. Physician communication and patient adherence to treatment: a meta-analysis. Med Care. 2009;47(8):826-834. 
25. DiMatteo MR. Social support and patient adherence to medical treatment: a meta-analysis. Health Psychol. 2004;23(2):207-218.

26. Johnson VR, Jacobson KL, Gazmararian JA, Blake SC. Does social support help limited-literacy patients with medication adherence? A mixed methods study of patients in the Pharmacy Intervention for Limited Literacy (PILL) study. Patient Educ Couns. 2010;79(1):14-24.

27. McGinnis B, Olson KL, Magid D, et al. Factors related to adherence to statin therapy. Ann Pharmacother. 2007;41(11):1805-1811.

28. Kaplan SH, Greenfield S, Ware JE Jr. Assessing the effects of physicianpatient interactions on the outcomes of chronic disease. Med Care. 1989;27(3):110-127.

29. Cegala DJ, Marinelli T, Post D. The effects of patient communication skills training on compliance. Arch Fam Med. 2000;9(1):57.

30. Martin LR, Di Matteo MR, Lepper HS. Facilitation of patient involvement in care: development and validation of a scale. Behav Med. 2001; 27(3):111-120.

31. Greenfield S, Kaplan S, Ware JE. Expanding patient involvement in care. Ann Intern Med. 1985;102(4):520-528.

32. DiMatteo MR. Enhancing patient adherence to medical recommendations. JAMA. 1994;271(1):79-83.

33. Maly RC, Leake B, Frank JC, DiMatteo MR, Reuben DB. Implementation of consultative geriatric recommendations: the role of patientprimary care physician concordance. J Am Geriatr Soc. 2002;50(8): $1372-1380$.

34. James M, Turner DA, Broadbent DM, Vora J, Harding SP. Cost effectiveness analysis of screening for sight threatening diabetic eye disease. Br Med J. 2000;320:1627-1631.

35. Divertie V. Strategies to promote medication adherence in children with asthma. MCN Am J Matern Child Nurs. 2002;27(1):10-18.

36. Stevens VJ, Glasgow RE, Toobert DJ, Karanja N, Smith KS. One-year results from a brief, computer-assisted intervention to decrease consumption of fat and increase consumption of fruits and vegetables. Am J Health Promo. 2002;16(3):129-134.

37. Sykes TA, Venkatesh V, Rai A. Explaining physicians' use of EMR systems and performance in the shakedown phase. J Am Med Inform Assn. 2011;18(2):125-130.

38. Schectman JM, Schorling JB, Nadkarni MM, Voss JD. Determinants of physician use of an ambulatory prescription expert system. Int J Med Inf. 2005;74(9):711-717.

39. Ouellette JA, Wood W. Habit and intention in everyday life: the multiple processes by which past behavior predicts future behavior. Psychol Bull. 1998;124(1):54-74.

40. Aarts H, Dijksterhuis A. Habits as knowledge structures: automaticity in goal-directed behavior. J Pers Soc Psychol. 2000;78(1):53-63.

41. Bamberg S, Ajzen I, Schmidt P. Choice of travel mode in the theory of planned behavior: the roles of past behavior, habit, and reasoned action. Basic Appl Soc Psych. 2003;25(3):175-187.

42. Levin AM, Dato-on MC, Manolis C. Deterring illegal downloading: the effects of threat appeals, past behavior, subjective norms, and attributions of harm. J Consum Behav. 2007;6(2-3):111-122.

43. Benner JS, Glynn RJ, Mogun H, Neumann PJ, Weinstein MC, Avorn J. Long-term persistence in use of statin therapy in elderly patients. JAMA. 2002;288(4):455-461

44. Jonikas MA, Mandl KD. Surveillance of medication use: early identification of poor adherence. J Am Med Inform Assoc. Epub 2011 Nov 19.

45. Tamblyn R, Reidel K, Huang A, et al. Increasing the detection and response to adherence problems with cardiovascular medication in primary care through computerized drug management systems: a randomized controlled trial. Med Decis Making. 2010;30(2):176-188.

46. Choo PW, Rand CS, Inui TS, et al. Validation of patient reports, automated pharmacy records, and pill counts with electronic monitoring of adherence to antihypertensive therapy. Med Care. 1999;37(9):846-857.

47. Hess LM, Raebel MA, Conner DA, Malone DC. Measurement of adherence in pharmacy administrative databases: a proposal for standard definitions and preferred measures. Ann Pharmacother. 2006;40(7/8): $1280-1288$.
48. Gustafson DH, Johnson PR, Molfenter TD, Patton T, Shaw BR, Owens BH. Development and test of a model to predict adherence to a medical regimen. J Pharm Technol. 2001;17(5):198-208.

49. Ajzen I. Residual effects of past on later behavior: habituation and reasoned action perspectives. Pers Soc Psychol Rev. 2002;6(2):107-122.

50. Wetzels G, Nelemans P, Schouten J, van Wijk B, Prins M. All that glisters is not gold: a comparison of electronic monitoring versus filled prescriptions - an observational study. BMC Health Serv Res. 2006;6(1):8

51. DiMatteo MR, Giordani PJ, Lepper HS, Croghan TW. Patient adherence and medical treatment outcomes: a meta-analysis. Med Care. 2002;40(9):794-811.

52. Monane M, Bohn RL, Gurwitz JH, Glynn RJ, Levin R, Avorn J. Compliance with antihypertensive therapy among elderly Medicaid enrollees: the roles of age, gender, and race. Am J Public Health. 1996;86(12):1805-1808.

53. Simpson SH, Johnson JA, Farris KB, Tsuyuki RT. Development and validation of a survey to assess barriers to drug use in patients with chronic heart failure. Pharmacotherapy. 2002;22(9):1163-1172.

54. Steiner JF, Prochazka AV. The assessment of refill compliance using pharmacy records: methods, validity, and applications. J Clin Epidemiol. 1997;50(1):105-116.

55. Valenstein M, Copeland LA, Blow FC, et al. Pharmacy data identify poorly adherent patients with schizophrenia at increased risk for admission. Med Care. 2002;40(8):630-639.

56. Christensen DB, Williams B, Goldberg HI, Martin DP, Engelberg R, LoGerfo JP. Assessing compliance to antihypertensive medications using computer-based pharmacy records. Med Care. 1997;35(11):1164-1170.

57. McNeil BJ, Hanley JA. Statistical approaches to the analysis of receiver operating characteristic (ROC) curves. Med Decis Making. 1984;4(2):137-150.

58. Rice ME, Harris GT. Comparing effect sizes in follow-up studies: ROC area, Cohen's d, and r. Law Hum Behav. 2005;29(5):615-620.

59. Beech AR, Craig LA, Browne KD, editors. Assessment and Treatment of Sex Offenders: A Handbook. UK: Wiley-Blackwell; 2009.

60. Bultman DC, Svarstad BL. Effects of pharmacist monitoring on patient satisfaction with antidepressant medications therapy. J Am Pharm Assoc. 2002;42(1):36-43.

61. Buntin MB, Jain AK, Mattke S, Lurie N. Who gets disease management? J Gen Intern Med. 2009;24(5):649-655.

62. Mattke S, Seid M, Ma S. Evidence for the effect of disease management: is $\$ 1$ billion a year a good investment? Am J Manag Care. 2007;13(12):670-676.

63. Verplanken B, Orbell S. Reflections on past behavior: a self-report index of habit strength. J Appl Soc Psychol. 2003;33(6):1313-1330.

64. Taitel M, Jiang J, Rudkin K, Ewing S, Duncan I. The impact of pharmacist face-to-face counseling to improve medication adherence among patients initiating statin therapy. Patient Prefer Adherence. 2012;6:323-329.

65. Courneya KS, Plotnikoff RC, Hotz SB, Birkett NJ. Social support and the theory of planned behavior in the exercise domain. Am J Health Behav. 2000;24(4):300-308.

66. Hsiao CJ, Hing E, Socey TC, Cai B. Electronic Medical Record/ Electronic Health Record Systems of Office-based Physicians: United States, 2009 and Preliminary 2010 State Estimates. Hyattsville, MD: National Center for Health Statistics; 2010.

67. Hsiao CJ, Hing E, Socey TC, Cai B. Electronic Medical Record/ Electronic Health Record Systems of Office-Based Physicians: United States, 2009 and Preliminary 2010 State Estimates Health E Stat. National Center for Health Statistics, Centers for Disease Control; 2010.

68. Kuperman GJ. Health-information exchange: why are we doing it, and what are we doing? J Am Med Inform Assoc. 2011;18:678-682.

69. Gooch P, Roudsari A. Computerization of workflows, guidelines, and care pathways: a review of implementation challenges for processoriented health information systems. JAm Med Inform Assoc. 2011;18: 738-748. 
Patient Preference and Adherence

Dovepress

\section{Publish your work in this journal}

Patient Preference and Adherence is an international, peer-reviewed, open access journal focusing on the growing importance of patient preference and adherence throughout the therapeutic continuum. Patient satisfaction, acceptability, quality of life, compliance, persistence and their role in developing new therapeutic modalities and compounds to optimize clinical outcomes for existing disease states are major areas of interest. This journal has been accepted for indexing on PubMed Central. The manuscript management system is completely online and includes a very quick and fair peer-review system. Visit http://www.dovepress.com/ testimonials.php to read real quotes from published authors.

Submit your manuscript here: http://www.dovepress.com/patient-preference-and-adherence-journal 